\title{
A cohort study on risk factors of high- density lipoprotein cholesterol hypolipidemia among urban Chinese adults
}

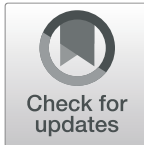

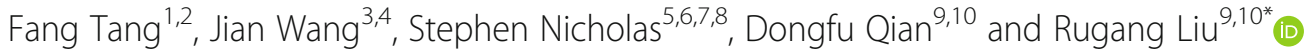

\begin{abstract}
Background: High-density lipoprotein cholesterol (HDL-C) hypolipidemia, a major type of dyslipidemia, has been associated with many kinds of diseases, such as stroke, coronary heart disease, obesity and diabetes, and has displayed an increasing prevalence in China. This study explores the risk factors of HDL-C hypolipidemia and makes recommendations for controlling and preventing HDL-C hypolipidemia and the diseases caused by it.
\end{abstract}

Methods: Using a retrospective cohort study design, 26,863 urban adults without dyslipidemia, diabetes, cardiovascular and cerebrovascular diseases, hepatosis, renal insufficiency and thyroid diseases were enrolled in the study between 2010 and 2015. Data on each individual were collected at the 2010 baseline year and at a follow-up medical check. A Cox regression model was constructed to evaluate the influence of potential risk factors on the outcome event- HDL-C hypolipidemia.

Results: The incidence of HDL-C hypolipidemia was 5.7\% (1531/26863). Sex, age, body mass index (BMI), HDL-C, triglyceride (TG) and urea nitrogen (UN) were significant risk factors of HDL-C hypolipidemia. Men were more likely to develop HDL-C hypolipidemia than women during follow-up medical checks ( $H R=1.258, P=0.014)$. The incidence of HDL-C hypolipidemia in the over 65 years old group was higher than that of the $\leq 65$ age group $(H R=1.276, P=$ 0.009). The incidence of HDL-C hypolipidemia increased with increasing $B M I(H R=1.030, P=0.002), T G(H R=1.321, P=$ $0.001)$ and $U N(H R=1.054, P=0.019)$, while falling with increasing $H D L-C$ in the baseline year $(H R=0.002, P<0.001)$.

Conclusions: Men, aged over 65, with high BMI were at the highest risk of developing HDL-C hypolipidemia. Measures should be taken to prevent $\mathrm{HDL}-\mathrm{C}$ hypolipidemia even for healthy urban adults whose blood biochemical indicators were in the normal range when their level of TG, UN and $\mathrm{HDL}-\mathrm{C}$ are closed to the border of the normal value range.

Keywords: High-density lipoprotein cholesterol hypolipidemia, Cox regression model, Urban Han Chinese adult, Cohort study

\footnotetext{
* Correspondence: rugangliu@njmu.edu.cn

${ }^{9}$ School of Health Policy \& Management, Nanjing Medical University, No. 101 Longmian Avenue, Jiangning District, Nanjing 211166, PR China

${ }^{10}$ Center for Global Health, Nanjing Medical University, No. 101 Longmian

Avenue, Jiangning District, Nanjing 211166, PR China

Full list of author information is available at the end of the article
}

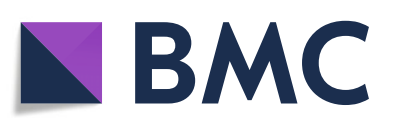

(- The Author(s). 2021 Open Access This article is licensed under a Creative Commons Attribution 4.0 International License, which permits use, sharing, adaptation, distribution and reproduction in any medium or format, as long as you give appropriate credit to the original author(s) and the source, provide a link to the Creative Commons licence, and indicate if changes were made. The images or other third party material in this article are included in the article's Creative Commons licence, unless indicated otherwise in a credit line to the material. If material is not included in the article's Creative Commons licence and your intended use is not permitted by statutory regulation or exceeds the permitted use, you will need to obtain permission directly from the copyright holder. To view a copy of this licence, visit http://creativecommons.org/licenses/by/4.0/. The Creative Commons Public Domain Dedication waiver (http://creativecommons.org/publicdomain/zero/1.0/) applies to the data made available in this article, unless otherwise stated in a credit line to the data. 


\section{Introduction}

Over the last 30 years, the incidence of dyslipidemia, or abnormal amount of lipids, such as triglycerides, cholesterol and fat phospholipids, in the blood has increased gradually in the Chinese population [1]. Opoku et al. [2] found the age- and sex-standardized prevalence of dyslipidemia was $43 \%$ for the Chinese population, with women having higher prevalence of dyslipidemia than men in both urban $(54.0 \%$ vs. $46.0 \%)$ and rural $(52.0 \%$ vs. $48.0 \%)$ locations. High-density lipoprotein cholesterol (HDL-C) hypolipidemia, a major dyslipidemia, had a prevalence as high as one-third of the Chinese population in 2012 [3]. Previous research has shown that HDL$\mathrm{C}$ hypolipidemia was strongly associated with stroke, coronary heart disease, obesity and diabetes [4-7], while higher levels of HDL-C was a protective factor of coronary heart disease and stroke [8].

HDL-C has usually been taken as an independent variable, with previous research on cardiovascular disease, kidney disease and metabolic syndrome [5, 7, 9-31], treating the ratio of triglyceride (TG) to HDL-C as an important factor to predict related diseases, such as hyperuricemia, long-term mortality, periodontal disease, and major adverse cardiovascular events (MACEs) [4, 32-39]. By identifying the risk factors of HDL-C hypolipidemia, the related diseases can be prevented and controlled. When taken as a dependent variable, previous studies have usually studied HDL-C hypolipidemia as part of dyslipidemia, rather than as a dependent variable itself [40-44]. Bi et al. [45] used ultrasound measurements of abdominal fat thickness to predict low HDL-C levels among Singaporean adult men and women. Drawing on the 2017 Korean National Health and Nutrition Examination Survey, Cho et al. [46] found that the HDL-C level showed a weak negative correlation with blood pressure and age, with women showing a sharper decrease in HDL-C with the increase in systolic blood pressure (SBP) and age than men. Also using Korean data, Cho et al. [47] found that the lowest income group showed a larger prevalence of low-HDL-C levels, and the male group showed a relatively mild decrease in the HDLC level after mid-life. Based on Spanish data, Millán-Núñez et al. [48] found that being females, having an elevated body mass index (BMI), using tobacco, suffering diabetes mellitus, displaying low-alcohol consumption and having a low exercise rate were significantly associated with low HDL-C. From a study of Sri Lankan patients, Weerarathna et al. [49] revealed females, younger age, higher BMI and lowdensity lipoprotein cholesterol level over $100 \mathrm{mg} / \mathrm{dL}$ had significant associations with suboptimal HDL among patients with diabetes mellitus.

A major constraint of most of above studies has been the use of cross-sectional data. Since the time when HDL-C hypolipidemia was diagnosed was unknown, time was not considered as an important confounding factor influencing the development of the disease. In crosssectional studies, all variables are measured at the same point in time, with no sequential order between independent variables and dependent variables. As a result, when there is a correlation between the independent and dependent variables, associations can be inferred, rather than causal relationships tested. By building a retrospective cohort database, the paper addresses this disadvantage, allowing causal conclusions to be drawn. Based on medical check-up data from Shandong, China, the paper analyzes the risk factors of HDL-C hypolipidemia among urban Han Chinese adults. Recommendations for controlling and preventing HDL-C hypolipidemia and its related diseases are also made.

\section{Methods}

\section{Data source and sample}

Data were obtained from the medical records of a routine health check-up program at the Centre for Health Management of the First Affiliated Hospital of Shandong First Medical University. Among the routine health check-up program, participants were asked about their medical history and abdominal ultrasound, thyroid ultrasound, electrocardiogram (ECG), electroencephalogram (EEG) or cardiac ultrasound performed, as well as laboratory analyses, including blood lipid, fasting blood glucose (FBG), liver function and renal function tests, undertaken. Based on those examination reports, the participants' health status were diagnosed by the physician and recorded on the health examination report.

The inclusion criteria for this study population were urban Han participants aged 18 and above, with records of at least two health check-ups over more than 1 year from January 2010 to December 2015 and the exclusion criteria were participants with dyslipidemia, diabetes, cardiovascular and cerebrovascular diseases, hepatosis, renal insufficiency and thyroid diseases diagnosed on their health examination report. Dyslipidemia was diagnosed as $\mathrm{TG} \geq 2.3 \mathrm{mmol} / \mathrm{L}$ ( $\geq 200 \mathrm{mg} / \mathrm{dl})$, and/ or low-density lipoprotein cholesterol $(\mathrm{LDL}-\mathrm{C}) \geq 4.1 \mathrm{mmol} / \mathrm{L}(\geq 160 \mathrm{mg} / \mathrm{dl})$, and/or total cholesterol $(\mathrm{TC}) \geq 6.2 \mathrm{mmol} / \mathrm{L}(\geq 240 \mathrm{mg} / \mathrm{dl})$, and/ or HDL-C $\leq 1.0 \mathrm{mmol} / \mathrm{L}(\leq 40 \mathrm{mg} / \mathrm{dl})$ and/ or selfreported clinically diagnosed dyslipidemia. Diabetes was diagnosed as $\mathrm{FBG} \geq 7.0 \mathrm{mmol} / \mathrm{L}(126 \mathrm{mg} / \mathrm{dl})$ and/ or selfreported clinically diagnosed diabetes. Cardiovascular and cerebrovascular diseases, hepatosis, renal insufficiency and thyroid diseases were also assessed by physician based on the corresponding diagnostic criteria. This cohort study comprised 26,863 urban Han adults.

\section{Outcome event}

The outcome event was HDL-C hypolipdemia. It was defined as $\mathrm{HDL}-\mathrm{C}$ lower than $1.0 \mathrm{mmol} / \mathrm{L}$ during a 
follow-up examination according to 2016 Chinese guidelines for the management of dyslipidemia in adults [1].

\section{Independent variables}

According to previous research, and constrained by the structure of health check-up records, data collected included sex, age, body mass index (BMI), blood pressure, FBG, blood lipid indices (HDL-C, TG, LDL-C), liver function indices (glutamic-pyruvic transaminase (ALT), glutamic oxalacetic transaminase (AST), $\gamma$-glutamyl transpeptidase $(\gamma-\mathrm{GT}))$ and renal function indices (creatinine $(\mathrm{Cr})$, urea nitrogen (UN), and uric acid (UA)). Smoking (yes/no) and drinking (yes/no) behaviors were included as covariates.

\section{Measurement of variables}

The hospital collected all medical check-up data under standardized procedures. Participants were required to wear light clothes and no shoes when their height and weight were measured. Nurses calculated BMI (weight $(\mathrm{kg})$ divided by squared height $\left(\mathrm{m}^{2}\right)$ ) and measured systolic blood pressure (SBP) and diastolic blood pressure (DBP) on the right arm of seated participants using Omron HEM-907 by the cuff-oscillometric method. Participants were required to fast at least $12 \mathrm{~h}$ before their venous blood samples were drawn, with FBG, blood lipid indices (HDL-C, TG, LDL-C), liver function indices (ALT, AST, $\gamma-\mathrm{GT})$ and renal function indices $(\mathrm{Cr}, \mathrm{UN}$, and UA) measured by the laboratory specialists using standard clinical and laboratory protocols in the national accredited laboratory of the First Affiliated Hospital of Shandong First Medical University. HDL-C was measured by the testing system Roche Cobase c701 using the direct method-catalase scavenging method. The respondents were divided into the $\leq 65$ age group and $>65$ age group.

\section{Statistical analysis}

Median (p50) and interquartile boundary values (p25, p75) were used to describe the continuous variables and percentages for categorical variables. The baseline characteristics between men and women were compared using Wilcoxon Rank-Sum (WRS) test for continuous variables and the chi-square test for categorical variables. Kaplan-Meier survival estimates and log-rank tests were used to analyze the differences of incidence density by sex and age. A Cox proportional hazards regression model was constructed to evaluate the influence of potential risk factors on HDL-C hypolipidemia, the outcome variable, diagnosed during follow-up health checks. First, independent variables were entered into the Cox regression model individually to explore the relationship between each independent variable and the outcome event. Next, a multiple Cox regression model was constructed, involving all independent variables that were significantly related to outcome event. All statistical analyses were performed using STATA SE, version 12.0.

\section{Results}

Baseline characteristics of respondents

Table 1 displays the characteristics of the 26,863 surveyed respondents in the baseline year (2010). Men comprised $53.27 \%$ of the respondents, with a median age of 41 (p25, p75: 32, 54), median height of $174 \mathrm{~cm}$ (p25, p75: 170, 178), median BMI of 24.49 (p25, p75: 22.45, 26.57); and women had a median age of 38 (p25, p75: 31, 47), median height of $163 \mathrm{~cm}$ (p25, p75: 160, 167), average BMI of 21.96 (p25, p75: 20.08, 24.13). There were significant differences between men and women across all variables $(P<0.001)$. Wilcoxon Rank-Sum and chi-square tests showed that all indicators including population characteristics, somatotype, blood pressure, blood glues, blood fat, liver function and renal function of men were higher than women, except HDL-C $(P<0.001)$.

\section{Survival time and incidence density}

The incidence of HDL-C hypolipidemia was 5.7\% (1531/ 26863), and the total incidence density of HDL-C hypolipidemia was 29.3/1000 person-years. Kaplan-Meier survival estimates in Fig. 1 and log-rank test in Table 2, show that the mean survival time for males was significantly smaller than females, the $>65$ age group survival time was smaller than the $\leq 65$ age group, and the incidence of male and the $>65$ age group was significantly higher than the reference group (log-rank test, $P<0.05$ ).

\section{Univariate cox regression model}

Single factor Cox regression models were constructed to analyze the relationship between the outcome event and each independent variable. Table 3 shows that there was a statistical correlation between HDL-C hypolipidemia and the independent variables, including sex, age, BMI, blood pressure factor, FBG, HDL-C, TG, LDL-C, ALT, $\gamma$ - GT, Cr, UN, UA $(P \leq 0.01)$, and marginally significantly correlated with AST $(P=0.056<0.1)$. The HDL-C hypolipidemia incidence of males in the $>65$ age group was higher than the $\leq 65$ age group. HDL-C hypolipidemia incidence increased with increasing BMI, blood pressure, blood glucose, liver function indicators, renal function indicators and TG and LDL-C blood fat indicators, but dropped with increasing HDL-C.

\section{Multivariate cox regression model}

All independent variables related to the outcome event $(P<0.1$ in single factor Cox regression) were entered into a Cox regression model. As shown in Table 4, sex, age, BMI, HDL-C, TG and UN were significant risk factors for the development of HDL-C hypolipidemia. Men 
Table 1 Baseline characteristics of respondents

\begin{tabular}{|c|c|c|c|c|c|c|}
\hline \multirow[t]{2}{*}{ Variables } & & \multirow{2}{*}{$\begin{array}{l}\text { Total } \\
\mathrm{M}(\mathrm{p} 25, \mathrm{p} 75) \\
/ \mathrm{N}(\%)\end{array}$} & \multirow{2}{*}{$\begin{array}{l}\text { Male } \\
M(p 25, p 75) \\
/ N(\%)\end{array}$} & \multirow{2}{*}{$\begin{array}{l}\text { Female } \\
\mathrm{M}(\mathrm{p} 25, \mathrm{p} 75) \\
/ \mathrm{N}(\%)\end{array}$} & \multirow[t]{2}{*}{$z / x^{2}$} & \multirow[t]{2}{*}{$P$} \\
\hline & & & & & & \\
\hline \multirow[t]{2}{*}{ Demographic characteristics } & Age (year) & $40(31,50)$ & $41(32,54)$ & $38(31,47)$ & 17.61 & $<0.001$ \\
\hline & Age group(> 65y) & $2140(7.97)$ & $1575(11.01)$ & $565(4.5)$ & 386.12 & $<0.001$ \\
\hline \multirow[t]{3}{*}{ Somatotype } & Height(cm) & $169(163,175)$ & $174(170,178)$ & $163(160,167)$ & 116.34 & $<0.001$ \\
\hline & Weight(Kg) & $66.3(58,76)$ & $74(67,81.5)$ & $58.5(53.5,64.5)$ & 105.7 & $<0.001$ \\
\hline & $\mathrm{BMI}(\mathrm{Kg} / \mathrm{m} \wedge 2)$ & $23.34(21.07,25.68)$ & $24.49(22.45,26.57)$ & $21.96(20.08,24.13)$ & 58.61 & $<0.001$ \\
\hline \multirow[t]{2}{*}{ Blood pressure } & $\mathrm{SBP}(\mathrm{mmHg})$ & $122(112,134)$ & $127(118,138)$ & $117(108,129)$ & 47.58 & $<0.001$ \\
\hline & $\mathrm{DBP}(\mathrm{mmHg})$ & $78(70,85)$ & $81(75,89)$ & $73(66,80)$ & 62.69 & $<0.001$ \\
\hline Blood glucose & $\mathrm{FBG}(\mathrm{mmol} / \mathrm{L})$ & $5.05(4.76,5.38)$ & $5.14(4.84,5.48)$ & $4.96(4.69,5.26)$ & 31.24 & $<0.001$ \\
\hline \multirow[t]{3}{*}{ Blood fat } & $\mathrm{HDL}-\mathrm{C}(\mathrm{mmol} / \mathrm{L})$ & $1.51(1.31,1.75)$ & $1.42(1.25,1.64)$ & $1.62(1.41,1.85)$ & -45.8 & $<0.001$ \\
\hline & $\mathrm{TG}(\mathrm{mmol} / \mathrm{L})$ & $0.92(0.69,1.22)$ & $1.03(0.79,1.32)$ & $0.8(0.61,1.07)$ & 47.12 & $<0.001$ \\
\hline & $\mathrm{LDL}-\mathrm{C}(\mathrm{mmol} / \mathrm{L})$ & $2.62(2.21,3.03)$ & $2.71(2.31,3.09)$ & $2.51(2.11,2.94)$ & 23.64 & $<0.001$ \\
\hline \multirow[t]{3}{*}{ Liver function } & $\mathrm{ALT}(\mathrm{U} / \mathrm{L})$ & $15.8(11.9,21.9)$ & $18.9(14.4,25.7)$ & $13(10.2,17)$ & 66.73 & $<0.001$ \\
\hline & $\mathrm{AST}(\mathrm{U} / \mathrm{L})$ & $17.8(14.8,21.3)$ & $18.9(16,22.7)$ & $16.4(13.8,19.5)$ & 43.27 & $<0.001$ \\
\hline & $\gamma-\mathrm{GT}(\mathrm{U} / \mathrm{L})$ & $16.8(12.1,25)$ & $22(16.4,31.4)$ & $12.7(10.1,16.6)$ & 86.03 & $<0.001$ \\
\hline \multirow[t]{3}{*}{ Renal function } & Cr(umol/L) & $67.6(57.4,78.4)$ & $77.3(70.5,84.3)$ & $57.1(51.9,62.7)$ & 122.45 & $<0.001$ \\
\hline & UN(mmol/L) & $4.7(4,5.6)$ & $5.1(4.4,6)$ & $4.3(3.6,5)$ & 59.71 & $<0.001$ \\
\hline & UA(umol/L) & $299.6(247.5,357.7)$ & $346.6(303.7,392.6)$ & $250.7(217.7,287)$ & 103.64 & $<0.001$ \\
\hline
\end{tabular}

were more likely to develop HDL-C hypolipidemia than women during follow-up medical checks among urban adults $(\mathrm{HR}=1.258, P=0.014)$. The incidence of HDL-C hypolipidemia in the $>65$ age group was higher than that of the $\leq 65$ age group ( $\mathrm{HR}=1.276, P=0.009)$; and the incidence of HDL-C hypolipidemia increased with increases in BMI $(\mathrm{HR}=1.030, P=0.002)$, TG $(\mathrm{HR}=$ 1.321, $P=0.001)$ and $\mathrm{UN}(\mathrm{HR}=1.054, P=0.019)$ and decreased with HDL-C increasing in baseline year $(\mathrm{HR}=$ $0.002, P<0.001)$.

\section{Discussion}

The present study explored the risk factors for the development of HDL-C hypolipidemia among urban Han Chinese adults. Sex, age, BMI, HDL-C, TG and UN in the baseline year were significantly associated with the

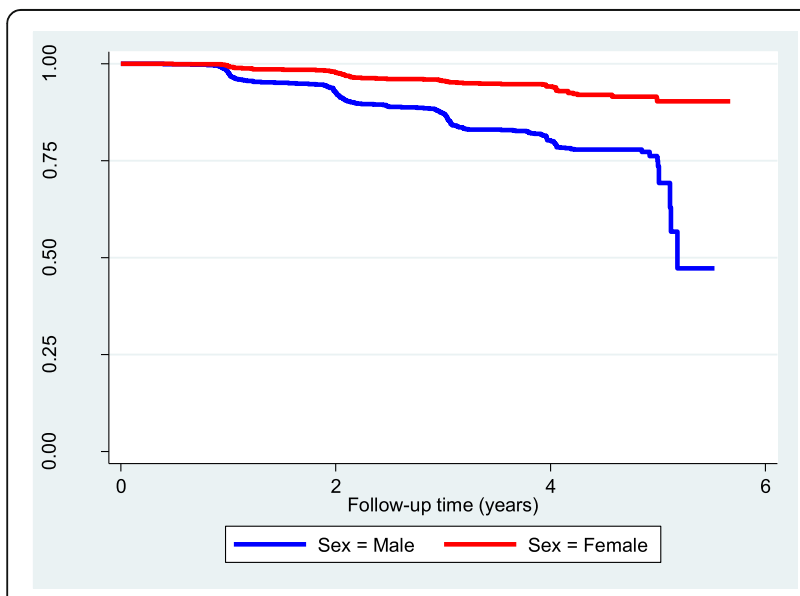

(a)

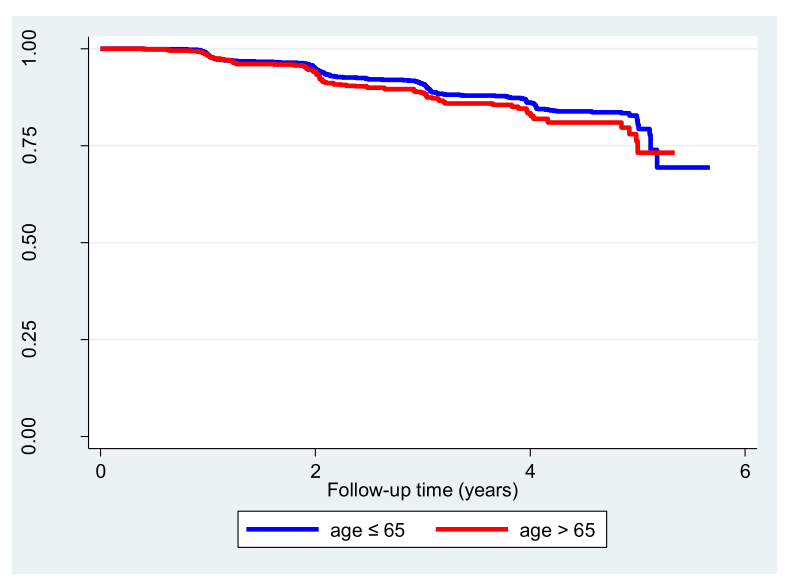

(b)

Fig. 1 a Kaplan-Meier survival estimates (sex); b Kaplan-Meier survival estimates (age) 
Table 2 Survival time and incidence density

\begin{tabular}{|c|c|c|c|c|c|c|}
\hline \multicolumn{2}{|c|}{ Variables } & \multirow{2}{*}{$\begin{array}{l}\text { Mean of survival time } \\
4.73\end{array}$} & \multirow{2}{*}{$\begin{array}{l}\text { SE } \\
0.05\end{array}$} & \multirow{2}{*}{$\begin{array}{l}\text { Incidence (\%) } \\
8.73\end{array}$} & \multirow{2}{*}{$\begin{array}{l}x^{2} \\
386.2\end{array}$} & \multirow{2}{*}{$\begin{array}{l}\boldsymbol{P} \\
<0.001\end{array}$} \\
\hline Sex & Male & & & & & \\
\hline & Female & 5.43 & 0.02 & 2.25 & & \\
\hline \multirow[t]{2}{*}{ Age } & $\leq 65$ group & 5.09 & 0.03 & 5.57 & 6.42 & 0.011 \\
\hline & $>65$ group & 4.78 & 0.05 & 7.24 & & \\
\hline
\end{tabular}

development of HDL-C hypolipidemia during follow-up medical checks. The incidence of HDL-C hypolipidemia was $5.7 \%$ during follow-up medical checks, which was lower than other studies, where the prevalence percentage varied between 33.9 and $60.86 \%[1,48,50]$. One reason was that previous samples comprised the entire population, while patients with metabolic diseases in this study were screened out in the baseline year. Males were 1.258 times as likely to have HDL-C hypolipidemia as females, which is different from the results of crosssectional studies [46-50]. There are two possible reasons. First, participants in this study were different from those in other studies. Patients with metabolic diseases were screened out in the baseline year, while previous studies contained the whole population. Women's morbidity of HDL-C hypolipidemia may be higher than men in the whole population at one point-in-time in crosssectional studies. The second difference is due to the statistical methods. Using the survival analysis method, the likelihood of developing the disease over time was explored based on cohort data while previous studies described the current situation of HDL-C hypolipidemia morbidity at a specific period of time. The difference between men and women in this study may be due to their different basic physical situation [49].
The present study showed that the over 65 year old group was more likely to suffer HDL-C hypolipidemia than the younger under 65 age group. Age differences in the prevalence of HDL-C hypolipidemia has been reported in other studies [1]. In a study of diabetes patients with the prevalence of low HDL cholesterol and its associations, Weerarathna et al. [49] did not find any age difference in the prevalence of HDL-C hypolipidemia. The heterogeneity on age needs to be further studied physiologically. Depending on the outcome of further studies, males aged over 65 might be an intervention target for the management of HDL-C hypolipidemia.

In regard to obesity, measured by BMI, HDL-C hypolipidemia in this study increased as BMI increased, which is similar to previous studies $[48,49]$. Keeping BMI as low as possible in the normal range is an effective way to prevent or attenuate the development of HDL-C hypolipidemia. Consistent with the present results, Cho et al. [46] also found an association between declining serum HDL-C and blood pressure and HDL-C hypolipidemia. This study also illustrated that HDL-C level in the baseline year had the greatest impact on the incidence of HDL-C hypolipidemia among all biological indicators, with HR only equal to 0.002 . Higher levels of

Table 3 Results of single factor Cox regression

\begin{tabular}{lllllll}
\hline Variables(Reference) & & $\boldsymbol{\beta}$ & SE & $\mathbf{z}$ & $\boldsymbol{P}$ & HR (95\%Cl) \\
\hline Population characteristics & Sex(Female) & 1.2204 & 0.0660 & 18.48 & $<0.001$ & $3.388(2.977,3.857)$ \\
& Age(S65 group) & 0.2143 & 0.0848 & 2.53 & 0.011 & $1.239(1.049,1.463)$ \\
Somatotype & BMI & 0.1499 & 0.0068 & 21.92 & $<0.001$ & $1.162(1.146,1.177)$ \\
Blood pressure & Blood pressure factor & 0.2547 & 0.0275 & 9.28 & $<0.001$ & $1.29(1.223,1.361)$ \\
Blood glucose & FBG & 0.2002 & 0.0377 & 5.31 & $<0.001$ & $1.222(1.135,1.315)$ \\
Blood fat & HDL-C & -6.6591 & 0.1505 & -44.24 & $<0.001$ & $0.001(0.001,0.002)$ \\
& TG & 1.6396 & 0.0714 & 22.98 & $<0.001$ & $5.153(4.481,5.927)$ \\
& LDL-C & 0.5210 & 0.0475 & 10.97 & $<0.001$ & $1.684(1.534,1.848)$ \\
Liver function & ALT & 0.0058 & 0.0006 & 10.35 & $<0.001$ & $1.006(1.005,1.007)$ \\
& AST & 0.0047 & 0.0025 & 1.91 & 0.056 & $1.005(1.000,1.010)$ \\
Renal function & Y- GT & 0.0033 & 0.0005 & 6.65 & $<0.001$ & $1.003(1.002,1.004)$ \\
& Cr & 0.0055 & 0.0005 & 11.20 & $<0.001$ & $1.005(1.005,1.006)$ \\
& UN & 0.1154 & 0.0189 & 6.10 & $<0.001$ & $1.122(1.081,1.165)$ \\
\hline
\end{tabular}


Table 4 Results of multiple Cox regression

\begin{tabular}{lllllll}
\hline Variables* (Reference) & & $\boldsymbol{\beta}$ & SE & $\mathbf{z}$ & $\boldsymbol{P}$ & HR (95\%Cl) \\
\hline Population characteristics & Sex(Female) & 0.229 & 0.094 & 2.45 & $\mathbf{0 . 0 1 4}$ & $1.258(1.047,1.511)$ \\
& Age(S65 group) & 0.244 & 0.093 & 2.62 & $\mathbf{0 . 0 0 9}$ & $1.276(1.063,1.532)$ \\
Somatotype & BMI & 0.030 & 0.010 & 3.10 & $\mathbf{0 . 0 0 2}$ & $1.030(1.011,1.050)$ \\
Blood pressure & Blood pressure factor & -0.021 & 0.036 & -0.59 & 0.557 & $0.979(0.912,1.051)$ \\
Blood glucose & FBG & 0.005 & 0.045 & 0.11 & 0.911 & $1.005(0.920,1.098)$ \\
Blood fat & HDL-C & -6.310 & 0.163 & -38.66 & $<\mathbf{0 . 0 0 1}$ & $0.002(0.001,0.003)$ \\
& TG & 0.278 & 0.085 & 3.25 & $\mathbf{0 . 0 0 1}$ & $1.321(1.117,1.561)$ \\
& LDL-C & 0.098 & 0.055 & 1.78 & 0.075 & $1.103(0.990,1.228)$ \\
Liver function & ALT & 0.004 & 0.003 & 1.35 & 0.177 & $1.004(0.998,1.009)$ \\
& AST & -0.004 & 0.006 & -0.74 & 0.461 & $0.996(0.985,1.007)$ \\
Renal function & Y- GT & 0.000 & 0.002 & 0.15 & 0.880 & $1.000(0.997,1.004)$ \\
& Cr & -0.005 & 0.002 & -1.94 & 0.053 & $0.995(0.990,1.000)$ \\
& UN & 0.052 & 0.022 & 2.34 & $\mathbf{0 . 0 1 9}$ & $1.054(1.009,1.101)$ \\
& UA & 0.001 & 0.000 & 1.74 & 0.082 & $1.001(1.000,1.001)$ \\
\hline
\end{tabular}

*Smoking and drinking behaviors were included as covariates

HDL-C in the baseline year could protect people from HDL-C hypolipidemia.

TG was the second strongly correlated variable with HDL-C hypolipidemia, followed by UN. The elevated level of TG and UN, and the decreased level of HDL-C in the baseline year, indicated an increased incidence of HDL-C hypolipidemia. Previous research has shown that it is essential to monitor lipid levels and to take interventions as early as possible to prevent dyslipidemia and its related complications [40]. The practical value of this study is that medical practitioners should not only focus on whether these indicators are within normal range or not, but also whether these indicators are close to the edge of the normal range. HDL-C hypolipidemia should not only be treated when it is diagnosed, but also preventive measures should be implemented when HDL-C hypolipidemia is on the margins of the normal values. Even for healthy people whose indicators are in the normal range, they should be advised to take measures to prevent HDL-C hypolipidemia when their indicators deviate from average levels.

\section{Comparisons with other urban areas in China}

Low HDL-C was treated as a part of dyslipidemia in most past research in China, rather than as an independent outcome [40,51]. While a few studies explored the risk factors of low HDL-C, they focused on comparing the difference between rural and urban residents [52, 53]. Most previous studies used cross-sectional data, with the prevalence of HDL-C hypolipidemia of Chinese urban residents, estimated at $20.8-28.4 \%$, and correlations between risk factors and low HDL-C reported [2, 52-54]. One contribution of this cohort study meant that the results comprised both the incidence and the causality of HDL-C hypolipidemia.

\section{Study strengths and limitations}

There are three major strengths in this study. First, this study built a cohort without metabolic diseases in the baseline year. This reduced the influence from other related diseases. Second, survival and cohort analysis methods were used to explore casual relationships, rather than correlations, between the dependent and independent variables. Third, more potential biochemical indicators were involved in the model.

This study has several limitations. First, lifestyle factors, such as diet and exercise habits, that may be associated with the occurrence of HDL-C hypolipidemia were not included in the dataset. Second, the short follow-up time period and low incidence density may affect the accuracy of Cox regression model. Third, the sample did not include rural residents where the incidence of dyslipidemia shows a tendency to rise more quickly than among urban residents. Finally, genetic information and family history related to cardiometabolic disorders were not included. These limitations might impose a modest constraint on the interpretation of these findings, but they should not substantively undermine the internal validity of the study.

\section{Conclusions}

Sex, age, BMI, HDL-C, TG and UN were significant risk factors in the development of HDL-C hypolipidemia. Men, aged over 65 years old, with higher BMI, were at a higher risk of developing HDL-C hypolipidemia than women younger than 65 years old and with lower BMI. Health management strategies should be taken to prevent HDL-C hypolipidemia, even for healthy urban adults whose blood biochemical indicators were in the normal range, when the level of TG, UN and HDL-C were closed to the border of the normal value range. 


\section{Acknowledgements}

The authors would like to thank the Editor and reviewers for constructive comments.

\section{Authors' contributions}

Conceptualization, Fang Tang and Rugang Liu; methodology, Fang Tang, Jian Wang and Rugang Liu; software, Rugang Liu; validation, Jian Wang and Stephen Nicholas; formal analysis, Rugang Liu; investigation, Fang Tang; resources, Jian Wang; data curation, Fang Tang and Rugang Liu; writing —original draft preparation, Fang Tang and Rugang Liu; writing - review and editing, Jian Wang, Stephen Nicholas and Dongfu Qian; supervision, Jian Wang, Stephen Nicholas and Dongfu Qian; project administration, Fang Tang; funding acquisition, Fang Tang, Stephen Nicholas and Rugang Liu. All authors have read and agreed to the published version of the manuscript

\section{Funding}

This research was funded by National Natural Science Foundation of China, grant number 71904089 and 71804093, and founded by NHC Key Laboratory of Health Economics and Policy Research (Shandong University), grant number NHC-HEPR2019006, and founded by Academic Promotion Programme of Shandong First Medical University, grant number 2019LJ005 \& 2019QL013.

\section{Availability of data and materials}

The datasets generated and/or analysed during the current study are not publicly available due to cooperation with the First Affiliated Hospital of Shandong First Medical University. The corresponding author will facilitate a discussion with First Affiliated Hospital of Shandong First Medical University for data access on a reasonable request.

\section{Ethics approval and consent to participate}

The study was approved by the Ethics Committee of Shandong Provincial Qianfoshan Hospital and written consent was obtained from all eligible participants. The study was carried out in accordance with the principles of the Declaration of Helsinki.

\section{Consent for publication}

Not applicable.

\section{Competing interests}

The authors declare no conflict of interest.

\section{Author details}

${ }^{1}$ Center for Big Data Research in Health and Medicine, The First Affiliated Hospital of Shandong First Medical University \& Shandong Provincial Qianfoshan Hospital, Jinan 250014, China. ${ }^{2}$ Shandong Provincial Qianfoshan Hospital, Cheeloo College of Medicine, Shandong University, Jinan 250014, China. ${ }^{3}$ Dong Fureng Economic and Social Development School, Wuhan University, No.54 Dongsi Lishi Hutong, Beijing 100010, Dongcheng District, China. ${ }^{4}$ Center for Health Economics and Management at School of Economics and Management, Wuhan University, 299 Bayi Road, Wuchang District, Wuhan 430072, Hubei Province, China. ${ }^{5}$ Australian National Institute of Management and Commerce, 1 Central Avenue Australian Technology Park, Eveleigh, Sydney NSW 2015, Australia. ${ }^{6}$ Guangdong Institute for International Strategies, Guangdong University of Foreign Studies, Baiyun Avenue North, Guangzhou 510420, PR China. ${ }^{7}$ School of Economics and School of Management, Tianjin Normal University, West Bin Shui Avenue, Tianjin 300074, China. ${ }^{8}$ Newcastle Business School, University of Newcastle, University Drive, Newcastle, NSW 2308, Australia. ${ }^{9}$ School of Health Policy \& Management, Nanjing Medical University, No. 101 Longmian Avenue, Jiangning District, Nanjing 211166, PR China. ${ }^{10}$ Center for Global Health, Nanjing Medical University, No. 101 Longmian Avenue, Jiangning District, Nanjing 211166, PR China.
Received: 6 December 2020 Accepted: 15 February 2021

Published online: 22 February 2021

\section{References}

1. Joint committee for guideline revision. 2016 Chinese guidelines for the management of dyslipidemia in adults. J Geriatr Cardiol. 2018;15:1-29. https://doi.org/10.11909/j.issn.1671-5411.2018.01.011.

2. Opoku S, Gan Y, Fu W, Chen D, Addo-Yobo E, Trofimovitch D, et al. Prevalence and risk factors for dyslipidemia among adults in rural and urban China: findings from the China National Stroke Screening and prevention project (CNSSPP). BMC Public Health. 2019;19:1500. https://doi.org/10.1186/ s12889-019-7827-5.

3. The website of National Health Commission of the People's Republic of China. Report on conditions of nutrition and chronic diseases of Chinese residents (2015). Available online: www.nhc.gov.cn/jkj/s5879/201506/450552 8e65f3460fb88685081ff158a2.shtml (Accessed on 8 Oct 2020). [In Chinese.]

4. Sultani R, Tong DC, Peverelle M, Lee YS, Baradi A, Wilson AM. Elevated triglycerides to high-density lipoprotein cholesterol (TG/HDL-C) ratio predicts long-term mortality in high-risk patients. Heart Lung Circ. 2020;29: 414-21. https://doi.org/10.1016/j.hlc.2019.03.019.

5. Jafari J, Daum A, Hamed JA, Osherov A, Orlov Y, Yosefy C, et al. Low highdensity lipoprotein cholesterol predisposes to coronary artery Ectasia. Biomedicines. 2019;7:79. https://doi.org/10.3390/biomedicines7040079.

6. Chen $\mathrm{T}$, Chen $\mathrm{H}$, Xiao H, Tang H, Xiang Z, Wang X, et al. Comparison of the value of neutrophil to high-density lipoprotein cholesterol ratio and lymphocyte to high-density lipoprotein cholesterol ratio for predicting metabolic syndrome among a population in the southern coast of China. Diabetes Metab Syndr Obes. 2020;13:597-605. https://doi.org/10.2147/ DMSO.S238990

7. Kim YG, Cho YR, Park GM, Won KB, Ann SH, Yang DH, et al. High-density lipoprotein cholesterol and the risk of obstructive coronary artery disease beyond low-density lipoprotein cholesterol in non-diabetic individuals. Eur J Prev Cardiol. 2020;27:706-14. https://doi.org/10.1177/2047487319844364.

8. Watanabe J, Kakehi E, Kotani K, Kayaba K, Nakamura Y, Ishikawa S. Highdensity lipoprotein cholesterol and risk of stroke subtypes: Jichi medical school cohort study. Asia Pac J Public Health. 2020;32:27-34. https://doi. org/10.1177/1010539519900685.

9. Weverling-Rijnsburger AW, Jonkers IJ, van Exel E, Gussekloo J, Westendorp RG. High-density vs low-density lipoprotein cholesterol as the risk factor for coronary artery disease and stroke in old age. Arch Intern Med. 2003;16: 1549. https://doi.org/10.1001/archinte.163.13.1549.

10. Baragetti A, Norata GD, Sarcina C, Rastelli F, Grigore L, Garlaschelli K, et al. High density lipoprotein cholesterol levels are an independent predictor of the progression of chronic kidney disease. J Intern Med. 2013;274:252-62. https://doi.org/10.1111/joim.12081.

11. Bowe B, Xie Y, Xian H, Balasubramanian S, Al-Aly Z. Low levels of highdensity lipoprotein cholesterol increase the risk of incident kidney disease and its progression. Kidney Int. 2016;89:886-96. https://doi.org/10.1016/j. kint.2015.12.034.

12. Cifuentes-Goches JC, Gómez-López J, Hernández-Ancheyta L, Flores-Fuentes SE, Incháustegui-Árias JL, Cañas-Urbina AO. Hypertriglyceridemia and low $\mathrm{HDL}$ cholesterol as high impact factors for metabolic syndrome diagnosis in apparently healthy adults. Rev Med Inst Mex Seguro Soc. 2012;50:301-6. 231 82260.

13. Freitas WM, Quaglia LA, Santos SN, de Paula RC, Santos RD, Blaha M, et al. Low HDL cholesterol but not high LDL cholesterol is independently associated with subclinical coronary atherosclerosis in healthy octogenarians. Aging Clin Exp Res. 2015;27:61-7. https://doi.org/10.1007/s4 0520-014-0249-4.

14. Haroun D, Mechli R, Sahuri R, AlKhatib S, Obeid O, El Mallah C, et al. Metabolic syndrome among adolescents in Dubai., United Arab Emirates., is attributable to the high prevalence of low HDL levels: a cross-sectional study. BMC Public Health. 2018;18:1-8. https://doi.org/10.1186/s12889-0186215-x.

15. Kawachi K, Kataoka H, Manabe S, Mochizuki T, Nitta K. Low HDL cholesterol as a predictor of chronic kidney disease progression: a cross-classification approach and matched cohort analysis. Heart Vessels. 2019;34:1440-55. https://doi.org/10.1007/s00380-019-01375-4.

16. Kim J, Lim DH, Han K, Kang SW, Ham DI, Kim SJ, et al. Retinal vein occlusion is associated with low blood high-density lipoprotein cholesterol: a 
Nationwide cohort study. Am J Ophthalmol. 2019;205:35-42. https://doi. org/10.1016/j.ajo.2019.04.001.

17. Lazo-Porras M, Bernabe-Ortiz A, Málaga G, Gilman RH, Acuña-Villaorduña A, Cardenas-Montero D, et al. Low HDL cholesterol as a cardiovascular risk factor in rural., urban., and rural-urban migrants: PERU MIGRANT cohort study. Atherosclerosis. 2016;46:36-43. https://doi.org/10.1016/j.a therosclerosis.2015.12.039.

18. Lu Q, Tian G, Zhang Y, Lu M, Lin X, Ma A. Low HDL-C predicts risk and PCI outcomes in the Han Chinese population. Atherosclerosis. 2013;226:193-7. https://doi.org/10.1016/j.atherosclerosis.2012.09.011.

19. Luo Y, Li J, Zhang J, Xu Y. Low HDL cholesterol is correlated to the acute ischemic stroke with diabetes mellitus. Lipids Health Dis. 2014;13:171. https://doi.org/10.1186/1476-511X-13-171.

20. LV Y, Ding XS, Li Y, An X, Miao LY. High BMl and low HDL-C predict the chemotherapy-related hepatic dysfunction in Chinese advanced NSCLC patients. Cancer Biomark. 2016;16:89-97. https://doi.org/10.3233/CBM-150544.

21. Madsen CM, Varbo A, Nordestgaard BG. Low HDL cholesterol and high risk of autoimmune disease: two population-based cohort studies including 117341 individuals. Clin Chem. 2019;65:644-52. https://doi.org/10.1373/ clinchem.2018.299636.

22. Mai W, Liu H, Liu X, Chen L, Zhou W. Low HDL-C levels are associated with cervicocerebral atherosclerotic stenosis in southern Chinese patients with large artery atherosclerotic ischemic stroke. Clin Neurol Neurosurg. 2018;171: 79-84. https://doi.org/10.1016/j.clineuro.2018.05.021.

23. Manandhar B, Cochran BJ, Rye KA. Role of high-density lipoproteins in cholesterol homeostasis and glycemic control. J Am Heart Assoc. 2020;9: e013531. https://doi.org/10.1161/JAHA.119.013531.

24. Matsuo T, Tashiro H, Sumiyoshi R, Yamamoto T, Oka-Miura Y, Matsumoto K, et al. Low high-density lipoprotein cholesterol (HDL) is a significant poor prognostic factor in malignant lymphoma. J Blood. 2017;130:5148.

25. O'Donovan G, Stensel D, Hamer M, Stamatakis E. The association between leisure-time physical activity, low HDL-cholesterol and mortality in a pooled analysis of nine population-based cohorts. Eur J Epidemiol. 2017;32:559-66. https://doi.org/10.1007/s10654-017-0280-9.

26. Pavanello C, Zheng KH, Schnitzler JG, Kroon J, Versloot M, Levels JH, et al. Low Hdl-cholesterol Levels are associated with a decreased monocyte activity and inflammation in carriers of Lcat mutation. J Atherosclerosis. 2019;287. https://doi.org/10.1016/j.atherosclerosis.2019.06.067.

27. Ramachandran Pillai R, Wilson AB, Premkumar NR, Kattimani S, Sagili $H$, Rajendiran S. Low serum levels of high-density lipoprotein cholesterol (HDLc) as an indicator for the development of severe postpartum depressive symptoms. PLoS One. 2018;13:e64395. https://doi.org/10.1371/journal.pone. 0064395.

28. Qian Y, Pu Y, Liu L, Wang DZ, Zhao X, Wang C, et al. Low HDL-C level is associated with the development of Intracranial artery stenosis: analysis from the Chinese IntraCranial AtheroSclerosis (CICAS) study. PLOS One. 2013; 8:e0192811. https://doi.org/10.1371/journal.pone.0192811.

29. Reiner Z, Muacević-Katanec D, Katanec D, Tedeschi-Reiner E. Low HDLcholesterol--an important risk factor for cardiovascular diseases. Lijec Vjesn. 2011;133:111 PMID: 21612108.

30. Rysz J, Gluba-Brzózka A, Rysz-Górzyńska M, Franczyk B. The role and function of HDL in patients with chronic kidney disease and the risk of cardiovascular disease. Int J Mol Sci. 2020;21:601. https://doi.org/10.3390/ ijms21020601.

31. Welty FK. How do elevated triglycerides and low HDL-cholesterol affect inflammation and atherothrombosis? Curr Cardiol Rep. 2013;15:400. https:// doi.org/10.1007/s11886-013-0400-4.

32. Chen C, Dai JL. Triglyceride to high-density lipoprotein cholesterol (HDL-C) ratio and arterial stiffness in Japanese population: a secondary analysis based on a cross-sectional study. Lipids Health Dis. 2018;17:130. https://doi. org/10.1186/s12944-018-0776-7.

33. Flowers E, Molina C, Mathur A, Reaven GM. Use of plasma triglyceride/highdensity lipoprotein cholesterol ratio to identify increased cardio-metabolic risk in young., healthy south Asians. Indian J Med Res. 2015;141:68-74. https://doi.org/10.4103/0971-5916.154506.

34. Ayako H, Fumiko K, Mio U, Yoshiko T, Kosaku N. Triglyceride to high-density lipoprotein cholesterol ratio predicts cardiovascular events in maintenance hemodialysis patients. Ren Replace Ther. 2016;2:60. https://doi.org/10.1186/ s41100-016-0069-4.

35. Kim JS, Kim W, Woo JS, Lee TW, Ihm CG, Kim YG, et al. Korea acute myocardial infarction registry investigators the predictive role of serum triglyceride to high-density lipoprotein cholesterol ratio according to renal function in patients with acute myocardial infarction. PLoS One. 2016;11: e0165484. https://doi.org/10.1371/journal.pone.0165484.

36. Lee MY, Hsiao PJ, Huang JC, Hsu WH, Chen SC, Chang JM, et al. Associations between triglyceride/high-density lipoprotein cholesterol ratio and micro- and macroangiopathies in type 2 diabetes mellitus. Endocr Pract. 2018;24:615-21. https://doi.org/10.4158/EP-2017-0254.

37. Chung TH, Kwon YJ, Lee YJ. High triglyceride to HDL cholesterol ratio is associated with low testosterone and sex hormone-binding globulin levels in middle-aged and elderly men. Aging Male. 2020;23:93-7. https://doi.org/1 0.1080/13685538.2018.1501015.

38. Kwon YJ, Park JW, Lim HJ, Lee YJ, Lee HS, Shim JY. Triglyceride to high density lipoprotein cholesterol ratio and its association with periodontal disease in Korean adults: findings based on the 2012-2014 Korean national health and nutrition examination survey. Clin Oral Investig. 2018:22:515-22. https://doi.org/10.1007/s00784-017-2140-0.

39. Liu XY, Wu QY, Chen ZH, Yan GY, Lu Y, Dai HJ, et al. Elevated triglyceride to high-density lipoprotein cholesterol (TG/HDL-C) ratio increased risk of hyperuricemia: a 4-year cohort study in China. Endocrine. 2020;68:71-80. https://doi.org/10.1007/s12020-019-02176-5.

40. Lian Y, Xie L, Liu Y, Tang F. Metabolic-related markers and inflammatory factors as predictors of dyslipidemia among urban Han Chinese adults. Lipids Health Dis. 2019;18:167. https://doi.org/10.1186/s12944-019-1109-1.

41. Bayram F, Kocer D, Gundogan K, Kaya A, Demir O, Coskun R, et al. Prevalence of dyslipidemia and associated risk factors in Turkish adults. J Clin Lipidol. 2014;8:206-16. https://doi.org/10.1016/j.jacl.2013.12.011.

42. Nuotio J, Pitkänen N, Magnussen CG, Buscot MJ, Venäläinen MS, Elo LL, et al. Prediction of adult dyslipidemia using genetic and childhood clinical risk factors: the cardiovascular risk in young Finns study. Circ Cardiovasc Genet. 2017;10:e001604. https://doi.org/10.1161/CIRCGENETICS.116.001604.

43. Nuotio J, Oikonen M, Magnussen CG, Viikari JS, Hutri-Kähönen N, Jula A, et al. Adult dyslipidemia prediction is improved by repeated measurements in childhood and young adulthood. The cardiovascular risk in young Finns study. Atherosclerosis. 2015;239:350-7. https://doi.org/10.1016/.ja therosclerosis.2015.02.004.

44. Yang X, Xu C, Wang Y, Cao C, Tao Q, Zhan S, et al. Risk prediction model of dyslipidaemia over a 5-year period based on the Taiwan MJ health checkup longitudinal database. Lipids Health Dis. 2018;17:259. https://doi.org/1 0.1186/s12944-018-0906-2.

45. Bi X, Loo YT, Henry CJ. Ultrasound measurement of intraabdominal fat thickness as a predictor of insulin resistance and low HDL cholesterol in Asians. Nutrition. 2018;55-56:99-103. https://doi.org/10.1016/..nut.2018.04.003.

46. Cho KH, Park HJ, Kim JR. Decrease in serum HDL-C level is associated with elevation of blood pressure: correlation analysis from the Korean National Health and nutrition examination survey 2017. Int J Environ Res Public Health. 2020;17:1101. https://doi.org/10.3390/ijerph17031101.

47. Cho KH, Park HJ, Kim SJ, Kim JR. Decrease in HDL-C is associated with age and household income in adults from the Korean National Health and nutrition examination survey 2017: correlation analysis of low HDL-C and poverty. Int J Environ Res Public Health. 2019;16:3329. https://doi.org/10.33 90/ijerph16183329.

48. Millán-Núñez J, Mantilla-Morató T, Toro R, Millán-Pérez JJ, Mangas-Rojas A, Scientific Committee of Hypertriglyceridemia Registry of Spanish Society of Arteriosclerosis (SEA). Cardiometabolic risk related to the association of hypertriglyceridemia-low HDLc. Curr Pharm Des. 2016;22:365-71. https://doi. org/10.2174/1381612822666151112150831.

49. Weerarathna TP, Herath H, Liyanage G. Prevalence of low HDL cholesterol and its associations among Sri Lankan patients with diabetes mellitus on statin therapy. Diabetes Metab Syndr. 2017;11:S253-6. https://doi.org/10.101 6/j.dsx.2016.12.040.

50. Toori AM, Kiani F, Sayehmiri F, Sayehmiri K, Mohsenzadeh Y, Ostovar R, et al. Prevalence of hypercholesterolemia, high LDL, and low HDL in Iran: a systematic review and meta-analysis. Iran J Med Sci. 2018;43:449-65 PMID: 30214097, PMCID: PMC6123550.

51. Zhang FL, Xing YQ, Wu YH, Liu HY, Luo Y, Sun MS, et al. The prevalence, awareness, treatment, and control of dyslipidemia in Northeast China: a population-based cross-sectional survey. Lipids Health Dis. 2017;16(1):61. https://doi.org/10.1186/s12944-017-0453-2 PMID: 28330492; PMCID: PMC5363017.

52. Frr Zhang M, Deng $Q$, Wang $L$, Huang Z, Zhou M, Li Y, et al. Prevalence of dyslipidemia and achievement of low-density lipoprotein cholesterol targets 
in Chinese adults: a nationally representative survey of 163,641 adults. Int J Cardiol. 2018;260:196-203. https://doi.org/10.1016/j.jicard.2017.12.069.

53. Xing $L$, Jing $L$, Tian $Y$, Yan $H$, Zhang B, Sun $Q$, et al. Epidemiology of dyslipidemia and associated cardiovascular risk factors in Northeast China: a cross-sectional study. Nutr Metab Cardiovasc Dis. 2020;30(12):2262-70. https://doi.org/10.1016/..numecd.2020.07.032.

54. Xiao L, Zhou Y, Ma J, Cao L, Wang B, Zhu C, et al. The cross-sectional and longitudinal associations of chromium with dyslipidemia: a prospective cohort study of urban adults in China. Chemosphere. 2019;215:362-9. https://doi.org/10.1016/j.chemosphere.2018.10.060 PMID: 30336313.

\section{Publisher's Note}

Springer Nature remains neutral with regard to jurisdictional claims in published maps and institutional affiliations.

Ready to submit your research? Choose BMC and benefit from:

- fast, convenient online submission

- thorough peer review by experienced researchers in your field

- rapid publication on acceptance

- support for research data, including large and complex data types

- gold Open Access which fosters wider collaboration and increased citations

- maximum visibility for your research: over $100 \mathrm{M}$ website views per year

At BMC, research is always in progress.

Learn more biomedcentral.com/submissions 